\title{
Os precedentes históricos da navegação aérea baseada em instrumentos: necessidade, surgimento e evolução
}

\section{The historical precedents for instrument-based air navigation: need, appearance and evolution}

\author{
Frederico de Araújo Portilho', Salmen Chaquip Bukzem² \\ Piloto Comercial. Bacharelando do 7º Período de Ciências Aeronáuticas pela Pontifícia Universidade Católica de Goiás (PUC-GO). <cmtefredericoportilho@gmail.com> \\ Graduado em Desenvolvimento de Sistemas de Informação e Especialista em Gestão de Segurança da Informação e Comunicações pela Universidade de Brasília. \\ Ex-militar da Força Aérea onde exerceu a função de Supervisor e Instrutor de órgãos de controle de tráfego aéreo, com atuação na prevenção e investigação \\ de Acidentes Aeronáuticos, Gerenciamento de Sistemas de Segurança Operacional, Inspeção em Prestadores de Serviço.de Navegação Aérea e instrução \\ em diversos cursos do SISCEAB.Professor do Curso de Ciências Aeronáuticas da Pontifícia Universidade Católica de Goiás.
}

Artigo apresentado à Pontifícia Universidade Católica de Goiás como exigência parcial para a obtenção do grau de bacharel em Ciências Aeronáuticas. Orientador Professor Esp. Salmen Chaquip Bukzem.

\begin{abstract}
RESUMO
Este trabalho apresenta um levantamento histórico a cerca da prática do voo por instrumentos, isto é, onde a navegação aérea é praticada sem que o piloto necessite de referencias com o horizonte externo à aeronave bem como sobre o terreno sobrevoado para que possa se orientar e localizar. São apontados os fatores históricos referentes a necessidade de se voar em condições de meteorologia adversas e período noturno, situações que justificaram a adoção de recursos que permitiriam o voo seguro das aeronaves mesmo em tais condições desfavoráveis. O desenvolvimento do trabalho traz de forma cronológica à implantação dos auxílios a navegação ao longo do mundo, destacando sua importância, detalhes técnicos e fatores que levaram a avanços e melhorias nos auxílios à navegação e procedimentos para pousos e decolagens, tal como durante o voo em rota. Ao longo da discussão histórica apresentada são dispostas de forma separada as características operacionais dos auxílios à navegação baseados em solo, já considerados defasados pelo fato de serem os primeiros colocados em serviço, assim como a necessidade de novas tecnologias de navegação aérea, discutidas na década de 1980 pela Organização da Aviação Civil Internacional (ICAO) através do comitê de Sistemas de Navegação Aérea do Futuro (FANS) o qual trouxe os conceitos de Comunicação, Navegação e Vigilância aérea baseados em satélites (CNS/ATM) de modo a otimizar e tornar mais eficiente o fluxo de tráfego aéreo no mundo todo, em especial em localidades de maior densidade.
\end{abstract}

PALAVRAS-CHAVE: Vôo por instrumentos; História da Aviação; Navegação aérea; Auxílios à navegação; Rádio-Navegação; CNS/ATM

Pontifical Catholic University of Rio Grande do Sul Porto Alegre, RS, Brazil

Editor

Thaís Russomano

Microgravity Centre PUCRS, Brazil

Executive Editor

Rafael Reimann Baptista

Faculdade de Educação Física e Ciências do Desporto, PUCRS, Brazil

e-ISSN: $2179-703 X$
Corresponding Author:

Frederico de Araújo Portilho

<cmtefredericoportilho@gmail.com>

Received: June 25, 2015

Accepted: October 20, 2015

(C) 2015 EDIPUCRS 


\begin{abstract}
This article presents a historical survey about the practice of instrument based flight, where air navigation is practiced without the pilot requirements to have references at the same time to the external horizon of the aircraft and on the airspace over so you can get your bearings and locate. The historical factors are pointed out concerning the need to fly in adverse weather conditions and at nighttime situations that justified the adoption of features that allow the safe flight of aircraft, even in such unfavorable conditions. The development work brings chronologically the implementation of aid to navigation throughout the world, highlighting its importance, technical details and factors that led to advances and improvements in navigation aids and procedures for takeoffs and landings, as while flying in route. Along the historical discussion presented are arranged separately, operating characteristics of navigational aids based on ground already considered outdated by being the first put into service, as well as the need for new air navigation technologies discussed in the decade of 1980 by the International Civil Aviation Organization (ICAO) through of the Future Air Navigation Systems Committee (FANS) which brought the concepts of Satellite-Based Communication, Air Navigation and Surveillance (CNS/ATM) in order to optimize and make more efficient air traffic flows worldwide, especially in higher-density locations.
\end{abstract}

KEYwORDS: Instrument-flight; Aviation history; Air navigation; Navigation-aid; CNS/ATM

\section{Introdução}

o estudo do contexto histórico de uma atividade permite o conhecimento dos fatores que a motivaram, a justificaram e contribuíram para seu cenário atual, assim a história pode trazer importantes respostas a cerca de uma atividade, não apenas se restringindo a datas, fatos e personagens importantes. Sem dúvida não se pode omitir tais fatores em um levantamento histórico, no entanto o âmbito fundamental da história é fornecer à sociedade explicações sobre ela mesma utilizando-se dispositivos próprios como à pesquisa e investigação (1).

Observa-se que cada vez mais, a história se relaciona com diversas áreas de conhecimentos, basicamente, é como se cada atividade, cada ramo de atuação ou interesse do homem tenha sua história contada. Isto se deve ao fato de que a humanidade busca por explicações, informações que dêem sentido e importância destas diversas áreas, através do conhecimento de fatos históricos de uma dada atividade (1).

A atividade aérea devido a sua complexidade técnica representa um importante exemplo desta situação por ter experimentado um exponencial desenvolvimento em tempo relativamente reduzido, especialmente no período entre as guerras mundiais. No âmbito da navegação aérea é importante explorar os precedentes que resultaram no surgimento de práticas específicas para se conduzir em voo de maneira segura as aeronaves em condições nem sempre favoráveis a visualização do horizonte externo e do terreno sobrevoado. Tal como durante meteorologia adversa ou período noturno, essas situações poderiam causar desorientação espacial nos pilotos devido à ausência de referencias com o horizonte, bem como possíveis colisões com obstáculos em razão da visibilidade prejudicada.

Segundo Monteiro (2), o avião assume importantes papéis positivos ao longo de sua história, como um instrumento de integração entre regiões que até antes do aprimoramento das aeronaves e dos processos de navegação, eram praticamente isoladas entre si. Através das aeronaves as distâncias no mundo entre os principais centros globais passam a ser superadas em tempo muito menor e de maneira mais segura e eficiente, comparadas a outros meios de transporte.

Ao passo que o uso comercial do avião é visto como uma grande possibilidade econômica e de integração entre as cidades e países, inicialmente para escoamento de correio aéreo e logo em seguida para o transporte de passageiros, a necessidade da implementação de "infraestruturas" aeronáuticas e aeroportuárias se faz presente, pois devido ao maior fluxo de aeronaves agora cumprindo uma malha comercial de vôos, seriam necessários recursos para permitir a correta navegação das aeronaves entre as cidades, bem como permitir pousos e decolagens mais seguros sem o risco de colisão das aeronaves com obstáculos e com outras aeronaves. Destaca Monteiro (2) que, com o término da Primeira Guerra Mundial a aviação comercial, tem como marco, o início de suas atividades no ano de 1919 com serviços de transporte aéreo postal na Alemanha.

A partir de então, a evolução das aeronaves e a necessidade de ligações aéreas cada vez mais distantes sobrevoando áreas inóspitas obrigou os países a implantarem "auxílios" no solo para que os pilotos pudessem se orientar e se localizar, principalmente no período noturno ou mediante condições de baixa visibilidade e camadas de nuvens baixas. 
Tais auxílios eram inicialmente tentativas de se "melhorar" a visualização e identificação dos pilotos de cidades que serviam de referência. Assim, os primeiros auxílios à navegação remontam à década de 1920, eram instalados no solo e consistiam de faróis balizadores (semelhantes aos encontrados em regiões costeiras e que orientam embarcações) com a finalidade de marcar as rotas do correio aéreo nacional. Tal sistema apresentava relativa confiabilidade para o voo no período noturno, mas ainda era pouco satisfatório para o vôo em condições meteorológicas adversas (3).

Ao longo do processo de evolução das aeronaves, percebe-se a constante necessidade de que estas pudessem permanecer em vôo cumprindo suas missões de transporte de passageiros e carga sem que houvessem preocupações relativas às condições meteorológicas, ao período do dia e das distâncias a serem vencidas. Assim, graças ao surgimento de equipamentos de auxílio à navegação aérea, o homem deixou de depender de processos unicamente visuais de orientação (4).

Os Estados Unidos foram precursores em meados da década de 1920 no âmbito do voo totalmente orientado por instrumentos, isto é, sem qualquer referência externa à aeronave para orientação e localização do piloto, no entanto várias situações ensejavam resoluções, a principal pairava sobre qual seria o método ou princípio de se orientar em voo sem observar cidades, rios, estradas ou acidentes geográficos.

Buscou-se, inicialmente, conceber instrumentos de vôo capazes de fornecer ao piloto uma confiável orientação referente a condição da aeronave com a linha do horizonte, isto é, se a aeronave estava voando nivelada, subindo, descendo ou fazendo curvas a esquerda ou a direita. Isto foi possível com o emprego de equipamentos giroscópios, assim como sistemas capazes de captar a pressão do ar externo à aeronave a fim de fornecer em instrumentos apropriados a altitude e velocidade da aeronave.

O projeto destes instrumentos, bem como sua idealização foram motivados por um estudo realizado no ano de 1925 por cientistas e especialistas do exército dos Estados Unidos preocupado com seus meios aéreos, onde o interessante seria pesquisar e desenvolver meios que proporcionassem o "blind flight" ou "voo cego" (4).

Este importante e revolucionário programa do exército dos Estados Unidos consistiu em um estudo técnico-científico iniciado no ano de 1925, o nome faz menção ao que se buscava como necessidade de navegação aérea, ou seja um voo sem referências visuais com o meio externo, orientado somente por instrumentos presentes a bordo da aeronave, temse assim basicamente um voo cego, sem que haja a necessidade do piloto em voltar seu olhar para fora da cabine de pilotagem da aeronave durante o voo (4).

\section{Os desafios relacionados ao advento dos instrumentos de navegação aérea e da rádio navegação}

A crescente demanda de utilização dos espaços aéreos para fins comerciais, já na década de 1920, em especial na América do Norte, Europa e África do Norte, resultou na importante necessidade da adoção de recursos para se navegar independentemente do período do dia ou ainda das condições meteorológicas, respeitando-se, no entanto condições absolutamente extremas, regras que são seguidas até os dias atuais e constituem valores mínimos de teto e visibilidade para operações de pousos e decolagens nos aeródromos os quais variam justamente em função dos auxílios à navegação empregados.

Os recursos para aperfeiçoar a navegação aérea passaram a ser discutidos no ano de 1925 . Tal como mencionado através de pesquisas do exército dos Estados Unidos, onde as conclusões iniciais apontaram a necessidade básica de alguns instrumentos para a realização de um voo orientado sem referencias externas à cabine de pilotagem além de uma infra-estrutura de auxílios à navegação (navaids) baseada no solo que fornecesse orientações para as aeronaves em voo. Tais orientações poderiam ser recebidas e interpretadas nos instrumentos de bordo (4).

Foram apontados três instrumentos indispensáveis para a realização de um voo totalmente orientado sem referências externas, onde o piloto poderia ainda se localizar a qualquer momento ao longo de seu voo em rota. O primeiro seria o altímetro, responsável por indicar a diferença vertical da aeronave com o nível do mar, ou com a superfície de pressão atmosférica ao qual estivesse ajustado. Assim o piloto poderia se separar mais efetivamente do terreno e obstáculos, os quais já passavam por classificações cartográficas, tendo suas elevações apresentadas em cartas e mapas aeronáuticos (5).

Em consonância a Wilkinson (6), o segundo item ou instrumento seria um horizonte artificial, que forneceria uma representação artificial do horizonte natural da terra, para que assim os aviadores pudessem ter uma orientação da atitude de vôo da aeronave, mesmo em dias de visibilidade reduzida, onde a linha do horizonte estaria encoberta por fenômenos meteorológicos, para isso foram empregados instrumentos giroscópios, sensíveis a tendências de giro da aeronave ao longo de seus eixos, foram concebidos, portanto o horizonte artificial e o indicador de curvas e derrapagens (6). 
Figura 1. Painel de instrumentos típico da década de 1930/40, onde pode-se observar os instrumento desenvolvidos ao longo da década de 1920, voltados para a orientação de vôo.

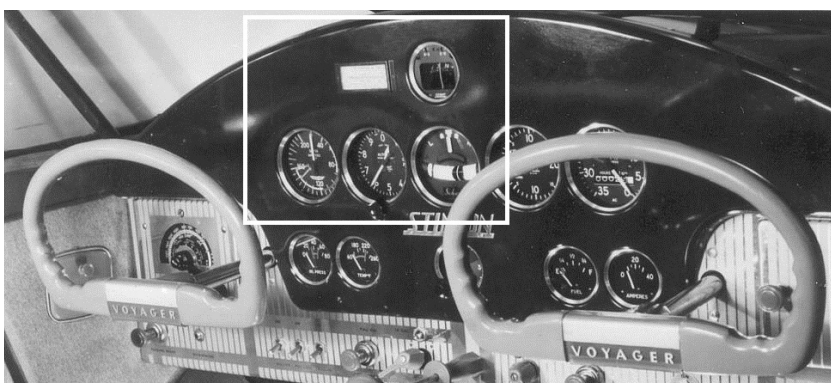

Fonte: $<$ http//: www.stinsonflyer.com $>$.

Destaca-se que, no dia 24 de setembro do ano de 1929, no campo de Mitchell Field em New York, Estados Unidos, o piloto militar americano James Doolittle foi o primeiro piloto da história a realizar um "blind flight", um voo conduzido sem referências visuais externas, onde a orientação foi obtida inteiramente através dos instrumentos de bordo, destacando-se o horizonte artificial e o giro direcional (4).

Figura 2. Painel da aeronave pilotada por James Doolittle, a primeira a realizar um vôo sem referências visuais externas, nota-se em destaque ao centro do painel o horizonte artificial. Esta aeronave ainda não dispunha de equipamentos de rádio navegação. No ano de 1929 seu vôo foi considerado como o primeiro vôo cego da história, pois obstruiu-se as janelas do cockpit e a orientação de vôo fez-se unicamente através de altímetro, velocímetro, giro direcional, bússola e horizonte artificial

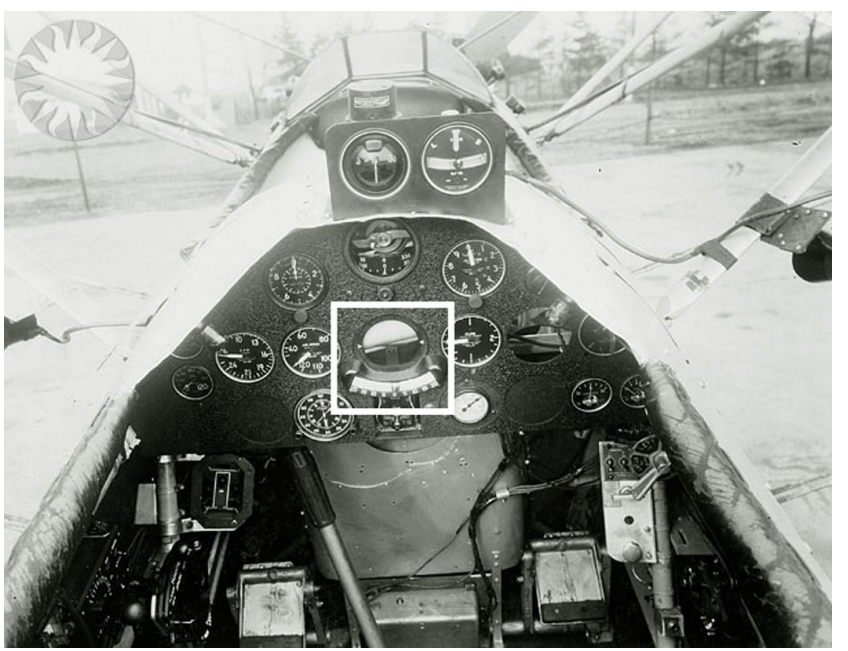

Fonte: $<$ http//: www.flickr.com $>$.

Ainda em referencia ao estudo do exercito dos Estados Unidos restava um terceiro instrumento para viabilizar a possibilidade concreta de se voar inteiramente uma rota sem que se dependesse da observação de referencias externas à aeronave, como pontos no solo.
Assim o terceiro instrumento necessário seria aquele capaz de proporcionar um processo de navegação que orientasse os pilotos ao longo de suas rotas, mantendo as aeronaves corretamente centradas em uma linha de rota entre duas ou mais localidades. Havendo a bordo tal instrumento não seria mais necessário, em aspecto algum olhar para fora da cabine de pilotagem a fim de se buscar orientação e localização ao longo do vôo, ao contrário do que se fazia, observando-se a geografia das localidades e as constelações de estrelas (4).

Surgiu, assim, a dúvida referente a como estabelecer uma ligação entre o instrumento de bordo e a infraestrutura de auxílios à navegação aérea instalados no solo, tal como já mencionado, os faróis luminosos refletores instalados no solo serviam como um marcador de posição das principais cidades e aeródromos, agregando relativos benefícios a aviação principalmente durante a navegação noturna. Porém esses faróis mostravam-se pouco satisfatórios durante condições adversas de meteorologia, pelo fato dos fenômenos obscurecedores, a exemplo de um nevoeiro, causarem a difusão do feixe de luz (3).

É descrito por Helfrick (4) que, com a popularização da transmissão comercial das ondas de rádio, iniciada no ano de 1920 nos Estados Unidos, vislumbrou-se a possibilidade de se embarcar nas aeronaves equipamentos rádiotransceptores, porém haviam grandes desafios a serem superados. Na década de 1920 praticamente inexistiam equipamentos eletrônicos a bordo das aeronaves, os motores da época ocasionavam grande vibração e os equipamentos rádio então existentes nunca haviam sido testados em tais condições.

A fim de que a aviação comercial pudesse se manter em operação mesmo em condições de tempo adverso, seria necessário um sistema que pudesse fornecer uma orientação precisa durante o vôo, sendo possíveis assim rotas cada vez mais longas, levando maior numero de passageiros e maior quantidade de carga. A melhoria dos processos de navegação mostrava-se também, portanto, uma necessidade comercial, para os países, empresas aéreas e fabricantes aeronáuticos, pois ao passo que existisse tecnologia que viabilizasse vôos que cobririam maiores distancias seria possível conceber aeronaves maiores e mais potentes, capazes de voar rotas mais longas.

Implementa-se, inicialmente, no ano de 1929 nos Estados Unidos a utilização das ondas de rádio para a finalidade de navegação aérea. Foram instalados, em solo, transmissores de ondas de rádio de baixa e média freqüência, chamados de rádio-faróis, para que as aeronaves equipadas com receptores adequados pudessem receber tais sinais e assim navegar de 
acordo com as orientações obtidas por intermédio da leitura dos instrumentos que indicavam rumos através das marcações rádio recebidas das antenas de solo.

A aviação experimenta sua primeira vertiginosa revolução no processo de navegação aérea em rota, pois, a partir de então, seria possível navegar recebendo sinais de orientação oriundos do solo, ao invés de buscar por referências visuais ou astronômicas para se localizar. O processo logo se expandiu para fora dos Estados Unidos, destacam-se como regiões pioneiras no uso deste sistema as Américas do Norte e Sul, França e Norte da África (3).

\section{O implemento e evolução dos auxílios à navegação baseados em solo: o surgimento dos rádio-faróis}

Os sistemas de navegação dependentes das ondas de rádio, possuem uma longa linha cronológica, desde seu humilde surgimento até os dias atuais da aviação. A partir da década de 1930, o implemento da radiocomunicação, bem como da radionavegação ou radiogoniometria permitiram diversas facilidades e melhorias na navegação aérea que até então não existiam, limitando as possibilidades das aeronaves se deslocarem em rota com eficiência e segurança. Os novos processos de navegação, baseados na emissão de ondas de rádio por estações transmissoras fixas baseadas no solo, ou rádio-faróis, tornaram possível a navegação aérea em rota através da orientação e localização da aeronave por meio das marcações de direção recebidas da estação de solo, um método revolucionário que rapidamente se difundiu pelo mundo e passou a equipar principalmente as aeronaves comerciais da época.

No contexto da propagação das ondas de rádio, é importante citar um breve precedente histórico relativo aos processos que tornaram possível a utilização de transmissores e receptores de ondas de rádio. No ano de 1864 o físico inglês James Maxwell desenvolveu a teoria a respeito da propagação das ondas de rádio, quatro anos mais tarde o físico alemão Heinrich Rudolf Hertz descobre a radiação eletromagnética e elabora aparelhos emissores e detectores de ondas rádio (7).

No ano de 1890 um francês, também físico, chamado Ebouard Branly inventa o receptor de ondas de rádio. Quatro anos mais tarde Alexander Stepanovich Popov, físico russo, concebe o circuito de antenas de transmissão rádio. Popov é tido como o inventor da antena de transmissão. Por fim, no ano de 1896, o italiano Gliugliermo Marconi reuni os equipamentos rádio já inventados e cria um sistema de transmissão rádio-telegráfica, podendo transmitir mensagens em código Morse sem o uso de fios, em 1901 consegue uma transmissão a longa distância entre a Inglaterra e St. Johns no Canadá, transmitindo a letra "S" (7).

Para Williams (8), com o desenvolvimento da tecnologia de propagação das ondas de rádio, tornase possível a partir da década de 1930 aplicar a nova tecnologia para as comunicações aeronáuticas, assim como para a navegação aérea com o uso de instrumentos, a rede dos primitivos rádio-faróis foram instalados inicialmente como um complemento aos faróis luminosos que marcavam as primitivas aerovias existentes no final de final da década de 1920 e início da década de 1930 (3).

Conhecidos nos Estados Unidos como airway beacons, estes "auxílios luminosos" à navegação eram instalados em intervalos de 10 a 15 milhas e possuíam um farol interno que rotacionava a seis revoluções por minuto, proporcionando um flash luminoso a cada dez segundos. Tais faróis emitiam luzes verdes ou vermelhas, os de luzes verde indicavam a direção da aerovia, assim como marcavam a posição de um campo de pouso. Os flashes luminosos poderiam também transmitir aos pilotos informações de navegação utilizando-se o código Morse (5).

Os rádio-faróis mais primitivos do início da década de 1930 consistiam apenas de um transmissor de um impulso sonoro em código Morse das letras A (. - ) e $N(-$.) recebido pela aeronave sintonizada na frequência da estação que possibilitava a navegação em apenas quatro cursos (ou rumos) a partir da estação, ou seja não existia ainda a possibilidade da navegação em um azimute completo de $360^{\circ}$ a partir da estação, as aeronaves deviam tomar uma das quatro direções possíveis a partir da estação, por tal razão ficou conhecido como Four Course Radio Beacon ou Rádio-Farol de Quatro Cursos, este sistema pioneiro é considerado predecessor aos rádio-faróis não direcionais ainda utilizados até hoje conhecidos como NDB ou Non Directional Beacon (9).

Apesar de satisfatório para manter a aeronave voando no eixo de uma rota aérea o sistema de rádiofarol de quatro cursos apresentava-se bastante simples e até mesmo vago, pois dependia-se de uma recepção e interpretação de sinal sonoro e sua tonalidade, o interessante seria integrar ao sistema um instrumento de bordo presente no painel de instrumentos, para que os pilotos pudessem a qualquer momento observar a posição da aeronave e se orientarem ao longo do voo. 
Mediante tal necessidade de melhorar o sistema de rádio faróis a fim de viabilizar aerovias ${ }^{1}$ de melhor e mais eficiente navegação, foi desenvolvido o Rádio Compasso ou RDF (Radio Directional Finder), instrumento de bordo, capaz de fornecer indicações da posição e marcações de direção recebidos de um Rádio-Farol através de uma agulha presente no instrumento, quando a agulha indicadora do rádio compasso estivesse centrada na linha de fé do instrumento significava que a aeronave estava voando no eixo de uma rota aérea ou aerovia, as quais eram constituídas por um dos quatro cursos emitidos pelos rádio-faróis de solo (3).

Mais tarde, porém ainda na década de 1930, os Rádio-Faróis também passaram por aperfeiçoamentos a fim de permitir a navegação em qualquer direção da rosa dos ventos, ou seja em um azimute completo. No entanto, o alcance do sinal não era ainda satisfatório, havendo a necessidade da instalação dos Radio-Faróis não direcionais em intervalos relativamente pequenos de distância.

Kayton e Fried (3) informam que as aerovias terrestres passaram a ser constituídas de seções longitudinais com espacejamento máximo entre os rádio-faróis de 200 milhas $^{2}$, ou cerca de 20 a 30 minutos de voo com a dependência de uma só antena. Voavase cerca de 100 milhas com a recepção de um sinal de cauda $^{3}$, para que, então a partir de um ponto de troca ${ }^{4}$, se passe a voar com a recepção de um sinal de proa ${ }^{5}$. As aerovias oceânicas eram definidas por cartas de navegação e não existiam auxílios rádio para apoio à navegação nas travessias oceânicas, pelo fato da necessidade de terra firme para se instalar um rádio-farol. Em tais travessias, os pilotos dependiam ainda de uma precisa navegação através de referencias astronômicas e equipamentos de cálculo de posição baseados neste método (3).

\footnotetext{
O termo Aerovia é utilizado para designar rotas aéreas pré definidas onde ao longo destas rotas estão presentes auxílios à navegação aérea baseados em solo, as aerovias podem também ser definidas como corredores de navegação aérea. Faz parte do planejamento de um voo por instrumentos a escolha de uma aerovia para o voo em rota. A consulta das aerovias para o planejamento de um voo é feito com as cartas aeronáuticas (10)

Milha terrestre é uma unidade padronizada de medida de distância adotada principalmente nos Estados Unidos, 1 milha terrestre equivale a 1,609 Km. Na aviação adota-se como padrão de medida de distâncias horizontais a milha náutica, onde 1 milha náutica equivale a $1,852 \mathrm{~km}$.

3 Sinal emitido por uma antena que já ficou para trás na rota da aeronave (10)

${ }^{4}$ Ponto de troca é para o vôo por instrumentos o ponto na rota onde se troca a sintonia de um auxilio de cauda por um auxilio de proa, a frente da aeronave (10)

Sinal emitido por uma antena que está a frente da aeronave ao longo de sua rota (10).
}

Ao longo da década de 1930, observa-se, principalmente nos Estados Unidos e Europa, a intensificação dos deslocamentos aéreos, motivados pelo surgimento de novas companhias aéreas e a então expansão no processo de fabricação das aeronaves, sendo possível e necessário o voo através de rotas de maior alcance.

O novo desafio passa a ser o constante aperfeiçoamento nos sistemas de rádionavegação, voltados à maior acuracidade dos sinais emitidos, além do alcance de uma estação. Em dias de tempo ruim, com tempestades, em que o sistema era mais requerido, havia significativas interferências entre a transmissão de solo e recepção dos sinais a bordo das aeronaves (4).

Ao passo que o alcance dos sinais pudesse ser aumentado e apresentasse poucos desvios, isto é, o chamado "curso firme" seria possível agregar maior eficiência à navegação aérea, evitando que as aeronaves gastassem maior tempo e combustível realizando correções ao longo do voo devido a desvios de rota, os quais em rotas de travessias oceânicas, por exemplo, eram bastante elevados, chegava no entanto o final da década de 1930, trazendo consigo o início da Segunda Guerra Mundial na Europa.

Figura 3. A constituição do sistema de rádio-faróis de quatro cursos, observa-se que uma antena instalada em solo podia emitir quatro sinais em direções distintas porém fixas formando assim quatro rotas aéreas ou aerovias. Os potentes rádio-faróis (transmissão de 1500 Watts) com operação na faixa de frequência de 100 a $500 \mathrm{kHz}$ eram instalados com um espaçamento de 200 milhas, ou seja cada rádio-farol ficava afastado de outro cerca de $320 \mathrm{~km}$.

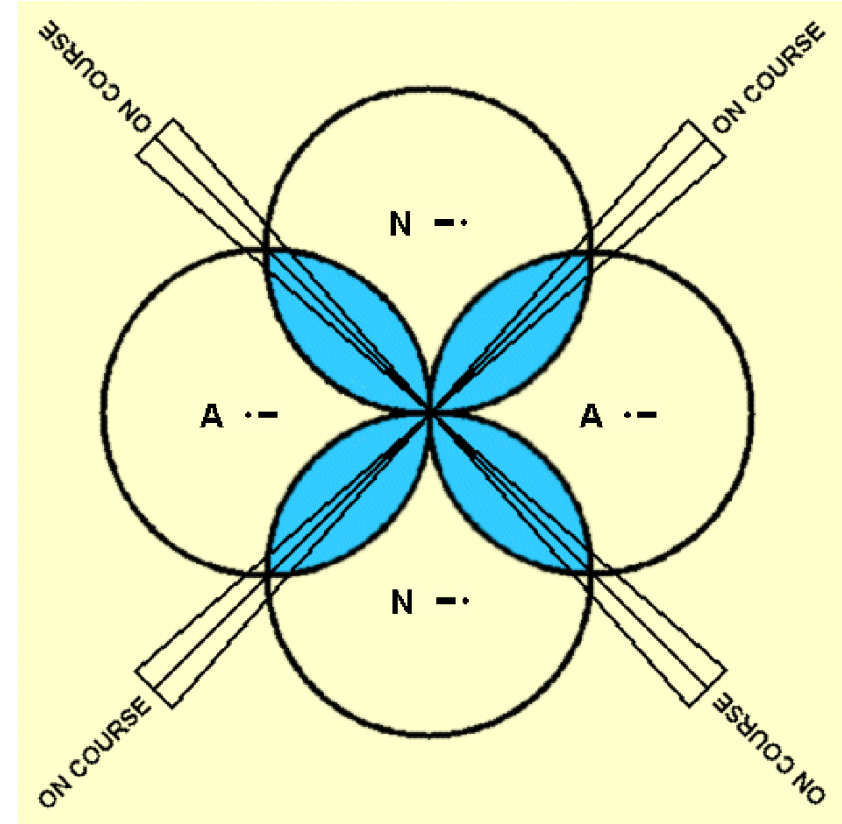

Fonte: <http://www.navfltsm.addr.com/ndb-nav-history.htm $>$. 
Figura 4. Rádio Compasso ou RDF (Radio Directional Finder), primitivo instrumento de rádio navegação aérea, pode-se observar a facilidade de leitura do mesmo e a simplicidade das informações fornecidas, como a situação lateral da aeronave com relação ao eixo de uma rota voada. A agulha centrada com a linha de fé, como se observa na figura demonstra o alinhamento da aeronave com relação ao rádio-faról em solo, estando assim voando no eixo (centro) de uma aerovia. No caso de desvios laterais com o eixo da aerovia a agulha estaria descentralizada com a linha de fé, se a aeronave estivesse por exemplo a esquerda do eixo da aerovia a agulha se deslocaria para a direita, indicando a necessidade de correção de proa para a direita.

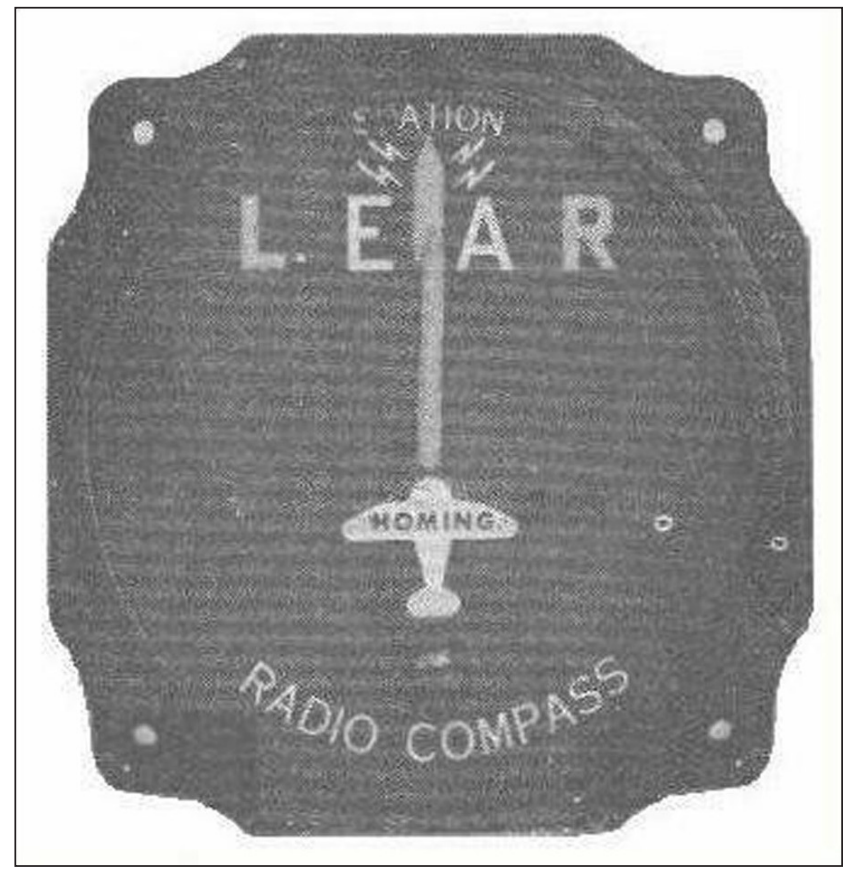

Fonte: <http://www.navfltsm.addr.com/ndb-nav-history.htm>.

De acordo com Monteiro (2), a Segunda Guerra Mundial, conflito de proporções nunca antes experimentadas pela humanidade, resultou na morte de mais de 16 milhões de soldados, contabilizando os países do eixo (como a Alemanha, Itália e Japão) e os países aliados (como os Estados Unidos e Inglaterra). Mais de 50 países estiveram envolvidos no conflito e estima-se que, na época, a guerra custou cerca de 1 trilhão de dólares americanos. Mesmo com todos os horrores e trágicas batalhas, por vezes desleais, que marcam uma guerra, pode-se dizer que a Segunda Guerra Mundial em muito contribuiu para a tecnologia aeronáutica, tanto no âmbito da construção de aeronaves e motores, quanto em recursos de navegação aérea.

Munson (11) informa que, com o final da Segunda Guerra Mundial no ano de 1945, ocorre um fenômeno semelhante ao observado com o término da Primeira Guerra Mundial, porém em maior escala, um excedente de aeronaves e pilotos. Porém, com substanciais refinamentos e aprimoramentos técnicos agregados às aeronaves e aos sistemas e recursos de navegação aérea, a aviação comercial poderia então combinar o excesso de aeronaves, mais modernas e robustas, com o excedente de aviadores, podendo, também, contar com melhores recursos de navegação, o que viria a permitir vôos mais longos, seguros e eficientes.

As aeronaves disponíveis no pós Segunda Guerra Mundial não eram essencialmente aeronaves projetadas para o transporte de passageiros e carga aérea. Nas linhas aéreas francesas e alemãs utilizavamse aeronaves de fabricação alemã concebidas como bombardeiros ou aeronaves de transporte de tropas, projetadas a cerca de uma década atrás. As aeronaves militares excedentes de guerra passariam por processos de conversão, se tornando aeronaves de transporte aéreo comercial. Tais conversões proporcionaram um enorme número de aeronaves disponíveis para as linhas aéreas comerciais em todo o mundo, sendo que a partir de meados da década de 1950, a aviação mundial entra na era dos jatos comerciais com o lançamento e gradual entrada em serviço do avião britânico DeHaviland Comet, e dos norte americanos Boeing 707, Convair Coronado e Douglas Aircraft DC-8 (11).

Assim como a tecnologia bélica contribuiu para o desenvolvimento de novas aeronaves, mais potentes, rápidas, capazes de voar muito mais alto e cobrir grandes distâncias, observa-se o desenvolvimento de novos meios e auxílios de navegação aérea e vigilância de tráfego aéreo, dentre os quais se destaca o radar de tráfego aéreo e a otimização das comunicações aeronáuticas, tais recursos até então voltados a meios militares, agora, com a reabertura pacífica dos céus convencionada pela Convenção de Chicago $^{6}$, estariam a serviço da aviação civil (12).

Novos sistemas de navegação aérea fariam parte do processo de expansão das atividades aéreas comerciais pelo mundo, devido à necessidade de meios mais precisos e confiáveis para a navegação aérea de longa distância, assim como para os deslocamentos aéreos em espaços aéreos cada vez mais movimentados (12).

Até o final da Segunda Guerra Mundial não ocorreram grandes avanços nos sistemas de navegação aérea. Ainda não havia meios capazes de orientar as aeronaves em aproximações e decolagens de aeroportos

\footnotetext{
${ }^{6}$ Conhecida como Convenção Internacional da Aviação Civil, foi realizada em Chicago de dezembro de 1944 a janeiro de 1945 por motivação do governo dos Estados Unidos, reunindo cinqüenta e duas nações as quais discutiram diversos temas de ordem técnica e operacional no âmbito da aviação civil internacional, visando a reabertura pacífica dos céus mediante o então término da Segunda Guerra Mundial. A Convenção de Chicago deu origem a diversas normas e métodos recomendados como práticas essenciais à aviação civil internacional, além de estabelecer a Organização Internacional da Aviação Civil - ICAO, atualmente sediada em Montreal - Canadá (10)
} 
em dias de baixa visibilidade e baixas camadas de nuvens, o avanço mais significativo foi o aprimoramento do rádio-farol de quatro cursos (A/N Radio Range) para o NDB ou rádio-farol não direcional. Assim, o instrumento de bordo que fornecia a orientação através das ondas recebidas de um rádio-farol evoluiu do RDF (ou rádio compasso) para o $\mathrm{ADF}^{79}$ (4).

De acordo com Helfrick (4), a navegação aérea em rota, em especial na América do Norte e Europa, estava bem apoiada pelos rádio auxílios (rádio-faróis) durante a década de 1930 até o final da Segunda Guerra Mundial, porém faltavam meios que auxiliassem os pilotos a decolar e pousar com maior segurança mediante condições meteorológicas contrárias. A deficiência em aproximações de baixa visibilidade era um fator que ainda atrapalhava consideravelmente o transporte aéreo comercial.

Durante a Segunda Guerra Mundial foram desenvolvidos sistemas de navegação que utilizavam ondas de rádio VHF (Very High Frequency). Com esta nova faixa de espectro de ondas de rádio, diminuíamse consideravelmente os problemas relacionados à qualidade de transmissão e possíveis interferências causadas por fenômenos atmosféricos, seria possível também a navegação aérea em cursos (rumos magnéticos) pré-determinados e disponíveis em um ângulo completo de 360 de direções magnéticas (4).

Passa-se a utilizar, portanto após a Segunda Guerra Mundial as ondas de rádio na faixa VHF para auxílios de navegação aérea, passando estes a contarem com o princípio de ondas onidirecionais, ou seja, linhas radiais orientadas pelo norte magnético, compondo um azimute completo de $360^{\circ}$ de direções a partir da posição da estação (ou rádio-farol direcional). Implementa-se assim a utilização do VOR (VHF Onidirecional Range) ou rádio-farol de alcance onidirecional ${ }^{810}$, um auxílio rádio concebido em tempos de guerra com tecnologia voltada para finalidades militares. Com o VOR já seria possível o voo em uma direção fixa selecionada pelo piloto, em qualquer uma das 360 linhas de direção magnéticas (conhecidas como radiais) que partem de uma estação VOR (9).

É descrito por Helfrick (4) que, a partir de então, os auxílios rádio padrões em aerovias passam a ser

\footnotetext{
ADF (Automatic Direction Finder) ou Buscador Automático de Direção, é o instrumento de rádio-navegação utilizado para a navegação em rota ou em procedimentos de subida ou aproximação com a orientação de um NDB. Ao se sintonizar a frequência de uma estação NDB no raio de alcance da aeronave o ADF automaticamente apontará para a estação através de uma agulha oscilante instalada dentro de um limbo graduado em 360 magnéticos (9).

${ }^{3} \mathrm{O}$ termo alcance onidirecional, faz menção a uma disposição em formato radial de $360^{\circ}$ de direções magnéticas do sinal emitido por uma estação, ou antena de VOR. Ou seja, um VOR emite seus sinais em todas as direções magnéticas (9).
}

os VOR (porém sem que fosse abandonado o NDB). Outro aspecto muito positivo com relação ao VOR, graças ao seu processo de navegação em radiais, seria sua utilização como auxílio para aproximações nos aeroportos operando com baixa visibilidade e teto, algo que antes de sua implementação ainda não era tecnicamente possível (4).

Figura 5. Representação de uma estação VOR [1] e suas linhas radiais [2] para navegação.

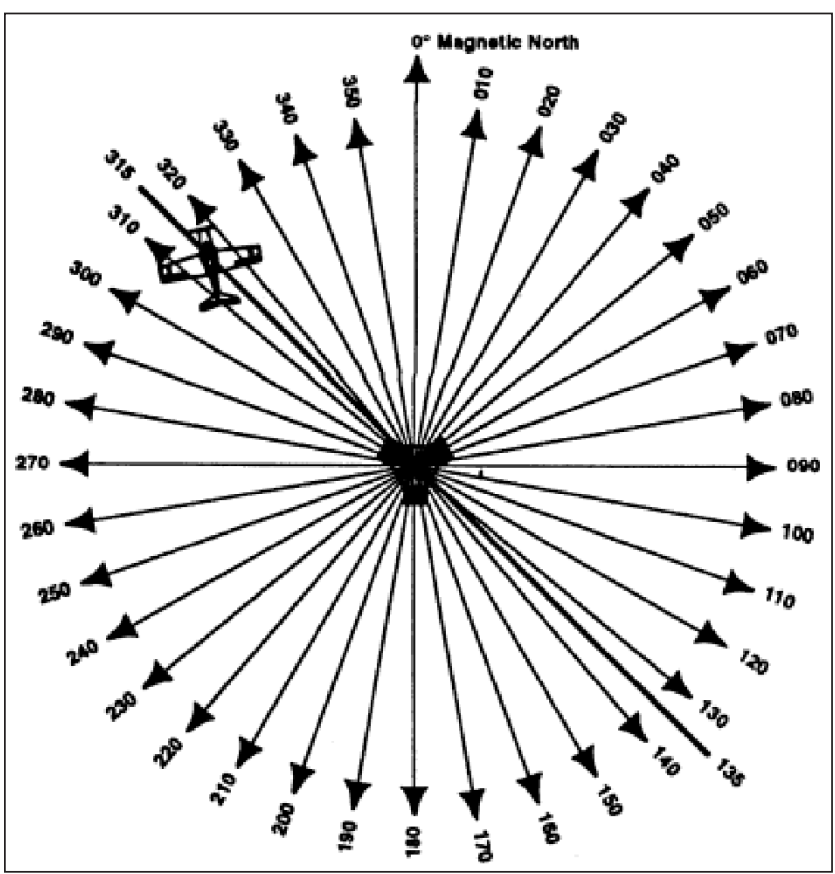

Fonte: <http:// www.rvs.uni-bielefeld.de $>$

Dentre a segunda metade da década de 1940 até o decorrer da década de 1950, as aerovias eram compostas por uma rede de auxílios rádio do tipo VOR e NDB e os procedimentos para aproximações e pouso nos aeródromos de maior tráfego eram apoiados por orientações de estações aeronáuticas no solo equipadas com radar que poderiam conduzir as aeronaves para um pouso relativamente seguro. Em complemento passa-se a utilizar procedimentos para pouso orientados por VOR, que, no entanto não eficazes para conduzir o piloto a um pouso seguro em situações de visibilidade e teto mais baixos, a exemplo, durante um denso nevoeiro (4).

Helfrick (4) ainda nos informa que, adicionalmente, se acoplou um transmissor $\mathrm{UHF}^{9}$ juntamente ao transmissor VHF, possibilitando assim um guia vertical de descida para as aeronaves em uma rampa

\footnotetext{
'Ultra High Frequency ou freqüência muito alta, espectro de transmissão de ondas hertzianas na faixa de 300 a $3.000 \mathrm{MHz}(7)$.
} 
de aproximação ${ }^{10}$, este guia denominado glide slope, possibilitava às aeronaves em aproximação final uma segura referência da descida a ser mantida de modo a se chegar a pista de maneira correta, sem manter uma aproximação alta ou baixa demais. Este sistema de pouso de precisão que combinava os transmissores VHF e UHF com orientações laterais e verticais de aproximação foi denominado de ILS (Instrument Landing System) ou sistema de pouso por instrumentos, que era composto ainda de um sofisticado sistema de luzes de brilho intenso (ou com flash) dispostas ao longo da reta final de aproximação, a fim de possibilitar que os pilotos contassem com uma transição entre a condição de vôo por instrumentos e a visualização da pista. Tal sistema foi denominado de Sistema de Luzes de Aproximação (ALS) e passou a ser um componente obrigatório nos procedimentos de aproximação por precisão, como o ILS.

\section{A constante necessidade por novas tecnologias de navegação: as rotas de longo curso, o Comitê FANS e o CNS/ATM}

Segundo Salvat (12) a navegação aérea em rotas sobre regiões povoadas se desenvolveu de maneira satisfatória, apoiada por auxílios rádio à navegação instalados no solo e próximos aos aeroportos, servindo de balizadores de aerovias, bem como auxílios para aproximações por instrumentos ao longo de meados dos anos de 1920 em diante.

No entanto, com os novos jatos comerciais de grande alcance e autonomia de voo, seriam necessários implementos nos recursos de navegação aérea de longo curso. As rotas transoceânicas, transdesérticas e transpolares apresentavam problemas relacionados à carência de instalações apropriadas que obtivessem uma cobertura eficaz destas amplas regiões remotas (12).

Países como Estados Unidos, Inglaterra e Alemanha desenvolveram, ao longo da Segunda Guerra Mundial, sistemas de navegação aérea de longo curso. Os Estados Unidos desenvolveram o LORAN, a Inglaterra o DECCA e a Alemanha o CONSOL. Todas as tecnologias voltadas ao apoio das atividades militares. O DECCA inglês, por exemplo, tinha como finalidade orientar as embarcações aliadas na operação do Dia D nas praias da Normandia na França (12).

\footnotetext{
${ }^{10}$ Trajetória descendente que conduz uma aeronave em aproximação até a pista de pouso, utilizando-se um adequado gradiente ou razão de descida, de acordo com o ângulo da rampa de aproximação, que é de geralmente $3^{\text {o }}(10)$.
}

Sistemas como o DECCA e o LORAN, conhecidos como sistemas hiperbólicos, foram desenvolvidos a fim de apoiar a navegação marítima e aérea de longo curso. Como a aviação comercial da década de 1950 voava cada vez mais rápida e cumprindo maiores distâncias graças aos novos motores a jato, fazia-se necessário aplicar tais recursos às rotas aéreas comerciais (3).

Apesar da disponibilização desses meios citados para a aviação comercial a partir de meados da década de 1950, o maior avanço em navegação aérea de longo curso foi o sistema de navegação inercial ou INS ${ }^{11}$ (Inercial Navigation System). Desenvolvido ao longo da década de 1950 a fim de orientar miras balísticas intercontinentais, é autônomo a meios externos, não necessitando de ondas de rádio para orientar a navegação e fornecer posições ao longo da superfície terrestre (3).

De acordo com Johnston (9), o sistema que gera informações de navegação conta com sensores, acelerômetros, giroscópios e computadores digitais que processam as informações recebidas dos componentes mencionados a fim de determinar a presente posição da aeronave, bem como fornecer indicações de rumo para próximas posições, baseando-se inclusive no sistema de coordenadas geográficas.

$O$ arranjo de navegação aérea no mundo passa a ser disposto de auxílios de solo como VOR e NDB ao longo das áreas continentais, balizando aerovias sobre os continentes, com maior presença destes auxílios nas áreas terminais ${ }^{12}$, as rotas em regiões remotas e oceânicas passam a ser baseadas pela navegação Inercial (12).

Com a crescente demanda de vôos, principalmente os comerciais, a estrutura de navegação aérea, bem como a utilização dos espaços aéreos já se mostrava defasada e ineficiente em face da grande demanda de vôos ao longo de todo o mundo. Assim no ano de 1983, a ICAO estabeleceu um comitê voltado às discussões relativas a sistemas de navegação aérea do futuro, sendo denominado de Comitê FANS (13).

Através do comitê FANS, foram estabelecidos novos conceitos para a aviação no âmbito da comunicação, navegação e vigilância além do gerenciamento de tráfego aéreo, com vistas à maior utilização e flexibilização dos espaços aéreos, tais conceitos foram denominados CNS/ ATM (Comunicação-Navegação-Vigilânciavinculados

\footnotetext{
${ }^{11}$ Também pode ser denominado IRS ou Sistema de Referência Inercial (Inercial Reference System) (3).

${ }^{12}$ Área terminal (TMA) corresponde a uma área de confluência de aerovias, que chegam e partem de aeroportos de grande movimento, mais de um aeroporto pode estar presente em uma área terminal. São áreas caracterizadas pelo grande tráfego aéreo, em fase de subida ou descida, o que torna a navegação aérea crítica e com maior necessidade de precisão em uma área TMA (10).
} 
ao Gerenciamento de Tráfego Aéreo), e determinam que tais funcionalidades (navegação, comunicação e gerenciamento do tráfego aéreo) viam a ser baseadas na utilização de satélites e não mais em auxílios e estações radar e de comunicações instaladas no solo (13).

No segmento da navegação, os procedimentos para o vôo em rota, bem como os procedimentos de chegada, aproximação e saída da terminal, passam, a partir de então, a migrar da rede de auxílios baseados em solo para a disponibilização de meios baseados em Sistemas de Satélites de Navegação Global ou GNSS onde a navegação das aeronaves e a execução de procedimentos passa a depender da Navegação Baseada em Performance (PBN - Performance-based Navigation) (13).

De acordo com Basílio et al. (13), a adoção do PBN é uma das principais soluções para os problemas decorrentes do aumento do número de aeronaves em operação, tendo em vista que, durante muitos anos, a navegação aérea utilizou-se de rotas balizadas pelos VOR, DME e NDB, equipamentos obsoletos no contexto evolutivo da aviação civil, tendo em vista que tais rotas caracterizam-se por serem fixas e ineficientes. O conceito de PBN, baseia-se na implementação da Navegação de Área ${ }^{13}$ (RNAV), associada à Performance Requerida de Navegação ${ }^{14}$ (RNP), isto é, a capacidade da aeronave em se manter dentro dos padrões de precisão exigidos para a navegação na rota em questão ou no procedimento a ser executado, por exemplo, durante uma saída ou aproximação do aeródromo.

No âmbito das comunicações e da vigilância de tráfego aéreo, associadas ao controle e gerenciamento de fluxo de tráfego aéreo (ATM), destaca-se a transmissão via satélite de dados através do enlace digital de mensagens instantâneas entre as aeronaves e estações de controle de tráfego aéreo (ATC), sistema conhecido como CPDLC (Controller Pilot Data Link Communications) (13).

Com relação à vigilância destacam-se no panorama do CNS/ATM, a vigilância automática dependente (ADS) e a multilateração, meios que visam aumentar a precisão na identificação das aeronaves permitindo maior flexibilização no uso dos densos espaços aéreos. O conceito da vigilância automática dependente estabelece que a aeronave possa transmitir de forma

\footnotetext{
${ }^{13}$ RNAV ou rotas de navegação de área consistem de rotas dispostas no espaço aéreo definidas pelas autoridades aeronáuticas responsáveis (no caso do Brasil pelo DECEA - Depto. Controle do Espaço Aéreo), caracterizando-se por não dependerem de auxílios rádio balizadores no solo, no entanto a aeronave disposta a voar nestas rotas deve possuir equipamentos de navegação adequados, de acordo com os conceitos de PBN e RNP.

${ }^{14} \mathrm{Em}$ termos práticos segundo a ICAO, RNP pode ser definido como "a meta de precisão de navegação necessária para se operar em um determinado espaço aéreo” (13).
}

contínua e automática sua posição, através de receptores dentro da área de alcance (ADS-B - broadcasting) ou através de satélites (ADS-C - contract), eliminando a necessidade dos radares, ainda utilizados, a precisão da posição pode ser garantida através do processo de multilateração (13).

O conceito da multilateração estabelece que estações terrestres instaladas próximas a um aeródromo de maior fluxo de tráfego, ou ainda ao longo de uma área terminal (TMA) receba os sinais de resposta do transponder ${ }^{15}$ e do ADS-B de uma aeronave, e através de um complexo processamento de dados conhecido como "Diferença do Tempo de Chegada" (TDOA) dos sinais realiza cálculos a fim de determinar a posição precisa da aeronave, baseando-se na diferença de tempo entre os intervalos de recepção dos sinais das diferentes estações (13).

\section{Conclusão}

A aviação civil apresenta uma rica e detalhada história que abrange vários segmentos. Este trabalho apresentou a história e a evolução da navegação aérea baseada no uso de equipamentos a bordo, o desenvolvimento de auxílios instalados no solo e os processos de navegação, comunicação e vigilância baseados principalmente em satélites.

É um fato historicamente comprovado que a crescente demanda por voos comerciais cada vez mais longos, sobrevoando áreas cada vez mais remotas a fim de proporcionar uma maior integração entre as cidades e países, desencadeou a necessidade da evolução dos meios de navegação, uma vez que o processo visual restringia o vôo aos períodos de bom tempo. A aviação comercial não poderia ficar "rendida" a voar somente durante o período diurno ou ainda então mediante boas condições meteorológicas. Assim, a partir de meados da década de 1920, o transporte aéreo comercial passa a existir de maneira concreta e são desenvolvidos meios que permitiriam um vôo seguro sem que a navegação aérea dependesse exclusivamente da visualização de referências no terreno.

As Guerras Mundiais trouxeram substanciais avanços às aeronaves bem como às tecnologias de navegação aérea. Observa-se ao longo desta história, que tais tecnologias, inicialmente militares, ao final dos conflitos foram disponibilizadas à aviação civil, contribuindo exponencialmente para o desenvolvimento de rotas aéreas mais precisas e eficazes.

\footnotetext{
${ }^{15}$ Equipamento que emite ondas de resposta mediante a onda de interrogação enviada por um radar de solo, fornecendo a posição, altitude e demais dados da aeronave em vôo.
} 
Tais tecnologias possibilitaram, desde então, a utilização mais racional dos espaços aéreos, que passaram a se mostrar cada vez mais densos. Verificou-se então, que os meios de navegação baseados em auxílios no solo apresentaram-se insuficientes e incapazes de atender as necessidades da aviação comercial.

Organizou-se assim, através da ICAO, no ano de 1983 o comitê FANS, que apresentaria os conceitos de CNS/ATM, onde, mesmo com o aumento do número de aeronaves, a segurança de voo poderia manter patamares elevados, devido principalmente a maior precisão de navegação nas rotas, procedimentos de aproximação e saída dos aeródromos mais simplificados e eficientes, além de meios mais estáveis e seguros de se estabelecer a vigilância e as comunicações com as aeronaves.

Pode-se dizer que a segurança da navegação aérea foi aumentada principalmente pelo fato destas novas tecnologias representarem meios de utilização mais simples, de maior facilidade de implantação e menores probabilidades de falhas.

O trabalho mostrou ainda que o dinamismo é um fator integrado à aviação e que as transformações neste setor são muito rápidas, principalmente no sentido tecnológico, para que as demandas sejam atendidas.

\section{Referências}

1. Borges VP. O que é história? Coleção Primeiros Passos. São Paulo: Brasiliense; 1996.

2. Monteiro RF. Aviação: construindo a sua história. Goiânia: Editora da UCG; 2002.

3. Kayton M, Fried WR. Avionics navigation systems. 2 ${ }^{\underline{a}}$ ed. New York: John Wiley \& Sons Inc.; 1997.

4. Helfrick, Albert. Principles of avionics. 2a ed. Leesburg: Avionics Communications Inc.; 2002.

5. Lankford TT. Understanding aeronautical charts. $2^{\underline{a}}$ ed. Blue Ridge Summit: TAB Books; 1996.

6. Wilkinson R. Aircraft structures and systems. London: Longman Publishing Inc.; 1996.

7. Avanzi DM. Radiocomunicação digital: sinergia, produtividade e a alta performance. São Paulo: Scortecci; 2010.

8. Williams JR. The art of instrument flying. Blue Ridge Summit: TAB Books; 2003.

9. Johnston J. Avionics for pilot. Shrewsbury: Airlife Publishing; 1998.

10. Junior P. Regulamentos de tráfego aéreo: vôo por instrumentos. 22 $2^{\mathrm{a}}$ ed. São Paulo: Editora ASA; 2008.

11. Munson K. Civil airliners since 1946. 2 $2^{\mathrm{a}}$ ed. London: Blandford Press; 1975.

12. Salvat. Biblioteca Salvat de grandes temas: A Aviação. Rio de Janeiro: Editora Salvat do Brasil; 1979.

13. Basílio et al. Controle de Tráfego Aéreo: Panorama Atual e Perspectivas. Revista Conexão Sipaer. 2011;2(3):113-129. 